\title{
Formation of oxidation products in edible vegetable oils analyzed as FAME derivatives by HPLC-UV-ELSD
}

Arturo Morales ${ }^{1}$, Susana Marmesat ${ }^{1}, \mathrm{M}^{\mathrm{a}}$ Victoria Ruiz-Méndez ${ }^{1}$, Gloria Márquez-Ruiz ${ }^{2}$ and Joaquín Velasco ${ }^{1, *}$

${ }^{1}$ Instituto de la Grasa, Consejo Superior de Investigaciones Científicas (CSIC),

Avda. Padre García Tejero, 4, E-41012 Sevilla, Spain

${ }^{2}$ Instituto de Ciencia y Tecnología de Alimentos y Nutrición, Consejo Superior de Investigaciones Científicas (CSIC), c/ José Antonio Novais, 10, E-28040 Madrid, Spain

*To whom correspondence should be addressed:

Telephone: +34954611550

Fax: $\quad+34954616790$

E-mail: jvelasco@ig.csic.es 


\section{Abstract}

2 Formation of lipid oxidation products was evaluated in dietary vegetable oils by using a

3 novel analytical approach that consisted of derivatization of TAG into FAME and

4 HPLC analysis with two detectors in series, UV and evaporative light scattering 5 detector (ELSD). Three sunflower oils with different contents of oleic and linoleic 6 acids, i.e. high-linoleic (HLSO), high-oleic (HOSO) and high-stearic high-oleic 7 (HSHOSO), and two oils containing linolenic acid, soybean (SbO) and rapeseed (RO) 8 oils, were heated at $40^{\circ} \mathrm{C}$ and analyzed up to the exhaustion of total tocopherols. Results

9 showed that oxidation products of linoleate were predominant in all cases, whereas no 10 significant formation of oleate oxidation products was observed in the five oils in the 11 presence of substantial contents of the tocopherols naturally occurring. Formation of 12 oleate hydroperoxides and monoepoxystearates derived from oleic acid was only 13 detected when tocopherols were exhausted in the monounsaturated oils, i.e., HOSO, 14 HSHOSO and RO. The analysis of the main oxidation products of linoleate by the 15 method applied proved to be a good analytical approach to evaluate the global oxidation 16 extent of oils containing oleic and linoleic acids as the only oxidizable substrates. The 17 method used enabled the quantitative determination of the simple hydroperoxydienes of 18 linoleate and linolenate as a whole. Results suggested occurrence of hydroperoxy 19 compounds other than those determined by the method in the oils containing linolenic 20 acid, showing the low stability of simple hydroperoxydienes and their participation in 21 further reactions.

22 Key-words: Hydroperoxides; hydroperoxydienes; autoxidation; FAME; ELSD 


\section{Introduction}

25 Autoxidation of food lipids generates a variety of products that impair the food flavor and may even be involved in chronic and degenerative diseases (Kanazawa, Sawa,

27 Akaike, \& Maeda, 2002). Unfortunately, the actual contribution of oxidized lipids coming from diet to diseases is at present unknown because their contents have not yet been defined and therefore it is not known whether they are sufficient to cause detrimental nutritional effects (Dobarganes and Márquez-Ruiz, 2003).

The qualitative analysis of the main oxidation products of the common dietary unsaturated fatty acids has been established using model lipid systems (Frankel, 2005).

On the other hand, studies dealing with quantitative analysis in foods are scarce. The principal limitations of the quantitative determination are due to a large number of compounds formed from numerous triacylglycerols (TAG), their low contents as individual species and their relatively low stability.

In a recent report, we have proposed a method of quantitative analysis for the main oxidation products of linoleic acid, i.e. hydroperoxy-, keto- and hydroxy- dienes, in oils by using a derivatization step to transform the TAG molecules into fatty acid methyl esters (FAME) and normal-phase HPLC-UV (Morales, Marmesat, Dobarganes, Márquez-Ruiz, \& Velasco, 2012a). With the transformation of TAG into FAME the number of analytes is drastically reduced and a considerable concentration effect arises as a result. The effect of the derivatization reaction to the analytes was thoroughly studied. Results showed that losses of hydroperoxydienes lower than $10 \mathrm{wt} \%$ occurred at the reaction conditions applied and that formation of keto- and hydroxy- dienes inevitably took place. An amount of $0.6-2.1 \mathrm{wt} \%$ of hydroperoxydienes was

47 transformed into keto- and hydroxy- dienes, being the formation of the former as much as three times higher. 
While the conjugated diene structure of the oxidation products of linoleic acid can be readily detected by absorption of UV light, those of oleic acid are not detected in the HPLC-UV analysis due to the absence of conjugated double bounds. The incorporation in series of an evaporative light scattering detector (ELSD) to the method was evaluated to examine its possibilities in the direct analysis of model lipids such as oxidized samples of FAME (Morales et al., 2012b). Results showed that the ELSD enables the global determination of the hydroperoxides of oleic and linoleic acid methyl esters. Connected in series with the UV detector, it makes it possible to determine both groups by difference. The ELSD also enabled the determination of the cis and trans forms of methyl 9,10-epoxystearate, which was indicative of methyl oleate oxidation.

The objective of the present study was to explore the possibilities of the HPLC-UVELSD method to evaluate formation of oxidation products in real samples of edible vegetable oils containing different contents of oleic, linoleic and linolenic acids, namely, high-linoleic sunflower oil (HLSO), high-oleic sunflower oil (HOSO), highstearic high-oleic sunflower oil (HSHOSO), soybean oil (SbO) and rapeseed oil (RO). For the first time in this series of analytical studies oxidation products of linolenic acid are dealt and the ELSD is applied to the analysis of oils, being a much more complex analytical matrix than the purified FAME previously studied (Morales et al., 2012b). A follow-up of oxidation at $40^{\circ} \mathrm{C}$ in the five oils was performed to study formation of compounds throughout the induction period, whose end is marked by the total exhaustion of the natural antioxidants, i.e. tocopherols. The samples were characterized by applying the specific extinction at $232 \mathrm{~nm}\left(\mathrm{~K}_{232}\right)$ and the peroxide value. Analysis of

71 polymers by high-performance size-exclusion chromatography (HPSEC) with 72 refractive-index detection was also performed as a rapid control measure to discard 
samples within advanced oxidation (Márquez-Ruiz, Martín-Polvillo, \& Dobarganes,

74 1996).

75

76

77

78

79

80

81

82

83

84

85

86

87

88

89

90

91

92

\section{Materials and Methods}

\subsection{Chemicals}

Methyl linolenate was purchased from Nu-Check-Prep (Elysian, MN, USA) and used as received. Diethyl ether stabilized with $1 \%$ v/v ethanol (Super purity solvent, HPLC grade) was acquired from Romil, LTD (Cambridge, UK) and n-heptane (99\% purity, HPLC grade) from Carlo Erba Reactifs-SDS (Val de Reuil, France). Both HPLC solvents were used as received. Any other chemical used was of analytical grade at least.

\subsection{Oil samples}

High-linoleic sunflower oil (HLSO), high-oleic sunflower oil (HOSO), high-stearic high-oleic sunflower oil (HSHOSO), soybean oil (SbO) and rapeseed oil (RO) were supplied by the group SOS Cuetara S.A. (Andújar, Jaén, Spain). The five oils were edible refined oils. The fatty acid compositions were $6.7 \% \mathrm{C} 16: 0,0.2 \% \mathrm{C} 16: 1,3.6 \%$ $\mathrm{C} 18: 0,33.0 \% \mathrm{C} 18: 1,55.2 \% \mathrm{C} 18: 2$ and $1.3 \%$ others for HLSO, $4.1 \% \mathrm{C} 16: 0,4.6 \%$ $\mathrm{C} 18: 0,77.6 \% \mathrm{C} 18: 1,11.7 \% \mathrm{C} 18: 2$ and $2.0 \%$ others for HOSO, $4.4 \% \mathrm{C} 16: 0,15.1 \%$ $\mathrm{C} 18: 0,71.8 \% \mathrm{C} 18: 1,5.0 \% \mathrm{C} 18: 2$ and $3.7 \%$ others for HSHOSO, $11.3 \% \mathrm{C} 16: 0,0.1 \%$ $\mathrm{C} 16: 1,3.5 \% \mathrm{C} 18: 0,22.5 \% \mathrm{C} 18: 1,54.6 \% \mathrm{C} 18: 2,6.1 \% \mathrm{C} 18: 3$ and 1.9\% others for SbO and $4.6 \% \mathrm{C} 16: 0,0.2 \% \mathrm{C} 16: 1,1.5 \% \mathrm{C} 18: 0,62.7 \% \mathrm{C} 18: 1,19.4 \% \mathrm{C} 18: 2,8.6 \% \mathrm{C} 18: 3$ and $3.0 \%$ others for RO.

\subsection{Methyl linolenate samples}

Three samples of $1 \mathrm{~g}$ of methyl linolenate containing different concentrations of $\alpha$ tocopherol were prepared, absence (control), $500 \mathrm{ppm}$ and $5 \mathrm{wt} \%$. The antioxidant was 
97 added directly for the more concentrated sample or in hexane. The hexane was evaporated with nitrogen and stirring under inert headspace with nitrogen was applied

99 in both cases.

\subsection{Oxidation conditions}

101 Aliquots of $20 \mathrm{~g}$ of the oils were placed in Petri dishes $(14.5 \mathrm{~cm}$ i.d.) open to the air and

102 oxidized at $40{ }^{\circ} \mathrm{C}$ in the dark in an oven with air circulation. A high surface-to-oil-

103 volume ratio $\left(7 \mathrm{~cm}^{-1}\right)$ guaranteed high oxygen availability and therefore non-limiting 104 oxygen conditions. Three independent samples were used in each oil. An aliquot of each 105 sample was taken in each sampling and the three aliquots were mixed and kept at $-35^{\circ} \mathrm{C}$ 106 until analyses. The samples were oxidized until the total depletion of tocopherols.

107 Aliquots of $1 \mathrm{~g}$ of the methyl linolenate samples were oxidized in beakers at ambient 108 temperature and in the dark using a surface-to-oil-volume ratio of $5 \mathrm{~cm}^{-1}$. The control 109 sample, i.e. without $\alpha$-tocopherol, was oxidized until the notorious occurrence of 110 complex chromatographic bands in the zone of hydroxydienes. The samples containing $111 \alpha$-tocopherol were oxidized until the simple hydroperoxydienes reached levels similar 112 to those of the control.

\section{$113 \quad 2.5$ Derivatization of oils}

114 Oxidized oil samples were transformed into FAME by transmethylation with $\mathrm{NaOMe}$ at 115 room temperature, according to a previous report (Morales et al., 2012a). A 300-mg 116 sample was accurately weighed into a screw-capped centrifuge tube $(13 \mathrm{~cm} \times 10 \mathrm{~mm}$ 117 I.D.) and a volume of $3 \mathrm{~mL}$ of tert-butyl methyl ether (TBME) was added. Then, a 1.5$118 \mathrm{~mL}$ volume of $0.2 \mathrm{M} \mathrm{NaOMe}$ was added, the tube closed, shaken for $1 \mathrm{~min}$, and allowed 119 it to stand for $2 \mathrm{~min}$. The solution was neutralized by adding $0.1 \mathrm{~mL}$ of $0.5 \mathrm{M} \mathrm{H}_{2} \mathrm{SO}_{4}$ in 120 methanol. Finally, $3 \mathrm{~mL}$ of distilled water was added, shaken for $10 \mathrm{~s}$ and centrifuged at 
$1215000 \mathrm{rpm}$ for $1 \mathrm{~min}$. The organic layer was separated, and then the solvent was

122 evaporated in a rotary evaporator at $40{ }^{\circ} \mathrm{C}$ and taken to dryness with a stream of 123 nitrogen. Solutions of FAME samples dissolved in hexane at a concentration of 1-50 $124 \mathrm{mg} / \mathrm{mL}$ were analyzed by HPLC.

126 The derivatized oil samples or oxidized methyl linolenate were analyzed in a Waters

127600 HPLC chromatograph. The chromatograph was equipped with a Waters 600 pump,

128 a Rheodyne injector valve (20- $\mu$ L sample loop), a silica HPLC column (LiChrospher ${ }^{\circledR}$

129 Si 60, 250 mm x 4 mm i.d., $5 \mu$ m particle size) (Merck, Darmstadt, Germany), an HP

1301050 Series variable wavelength UV detector (8 $\mathrm{mm}$ path length) (Agilent Technologies

131 Inc., Palo Alto, CA), a Waters 2424 Evaporative Light Scattering detector (ELSD), an

132 Agilent 35900E A/D Converter (Agilent Technologies Inc.) and a Waters 600

133 controller. The separation of analytes was performed in isocratic elution using n-

134 heptane:diethyl ether $(82: 18$, v/v) with a flow rate of $1 \mathrm{~mL} / \mathrm{min}$. Ethanol present in

135 diethyl ether as a stabilizer was not removed. Hydroperoxy- and hydroxy- dienes were

136 recorded by the UV detector at $234 \mathrm{~nm}$, while ketodienes were at $268 \mathrm{~nm}$. The ELSD

137 conditions applied were $35^{\circ} \mathrm{C}$ for nebulizer temperature, $40^{\circ} \mathrm{C}$ for tube temperature and

13825 psi for gas flow. The gas used for nebulization was nitrogen (purity 99.99\%). The

139 gain was set at 50. Quantitative data by the UV detector were obtained by applying

140 response factors reported elsewhere (Morales, Dobarganes, Márquez-Ruiz, \& Velasco,

141 2010), while external calibration was applied for quantitative determination of

142 compounds by the ELSD (Morales et al., 2012b). 
146 Analysis of TAG polymers in oils was performed by HPSEC with refractive index detector

147 according to IUPAC standard method 2.508 (IUPAC, 1992).

$148 \quad 2.8$ Peroxide value

149 Peroxide value was determined by the iodometric assay according to IUPAC standard 150 method 2.501 (IUPAC, 1992). Oil samples of $500 \mathrm{mg}$ and $1 \times 10^{-2} \mathrm{M} \mathrm{Na}_{2} \mathrm{~S}_{2} \mathrm{O}_{3}$ solution 151 were used.

153 Specific extinction at $232 \mathrm{~nm}$ was determined in cyclohexane as a measure of total

154 conjugated dienes according to AOCS standard method Ch 5-91 (AOCS, 1998).

\section{$155 \quad 2.10$ Analysis of tocopherols}

156 Analysis of tocopherols was carried out by normal-phase HPLC with fluorescence

157 detection following IUPAC standard method 2.411 (IUPAC, 1992).

\subsection{Statistical analysis}

159 The oil samples were analyzed in triplicate to determine lipid oxidation products by

160 HPLC and results were expressed as mean values followed by the standard deviation.

161 For the other analytical determinations the oil samples were analyzed in duplicate and

162 results were expressed as mean values. Comparisons of means were performed by the

163 Student's $t$ test using SPSS Statistics 17.0 (SPSS Inc., Chicago, IL, USA). Significance

164 was defined at $p<0.05$. 


\section{Results and Discussion}

167 Oils containing oleic and linoleic acids as oxidizable substrates

168 Three sunflower oils, HLSO, HOSO and HSHOSO, were chosen in this study because 169 they contained oleic and linoleic acids as the only oxidizable fatty acids at significant 170 concentrations and because of their different contents in these two substrates. The oils

171 were oxidized at $40^{\circ} \mathrm{C}$ and analyzed along their induction periods (IPs), whose end is 172 determined by the exhaustion of antioxidants, i.e. tocopherol, and a sharp increase in the 173 content of polymerization compounds (Márquez-Ruiz and Dobarganes, 2005). The 174 samples analyzed at the end of the assay presented amounts of $\alpha$-tocopherol equal or 175 close to zero and concentrations of polymers that increased approximately in $1 \%$ with 176 respect to the initial samples.

177 The three oils presented very low peroxide values (PVs), which were typical of fresh 178 refined oils $(<10 \mathrm{meq} / \mathrm{kg}$ ) (Tables 1-3). As observed in a previous report (Morales et 179 al., 2012a), minor amounts of hydroperoxy-, keto- and hydroxy- dienes were recorded 180 by UV in the fresh oils, showing slight incipient oxidation. As expected, the ELSD did 181 not enable to detect the low amounts of compounds found by UV in the initial samples, 182 due to a much lower sensitivity (Morales et al., 2012b).

183 The quantitative analysis of hydroperoxides by light scattering detection was possible in 184 the oxidized oils. As it will be dealt later, significant differences between the 185 concentrations of hydroperoxides found by UV and light scattering detection were not 186 found in the oils along the IPs (Tables 1-3). Nevertheless, the concentrations of 187 hydroperoxides determined by the ELSD in the two monounsaturated oils, i.e. HOSO and HSHOSO, were significantly larger than those by UV in samples of advanced oxidation, suggesting the formation of oleic hydroperoxides (Morales et al, 2012b). The 
190 ELSD also enabled the evaluation of ketodienes from concentrations larger than 0.4

$191 \mathrm{mg} / \mathrm{g}$ oil and the results obtained (not shown) were similar to those determined by UV.

192 Regarding hydroxydienes, the amounts found by UV were below the limit of

193 quantification in the ELSD (0.9 mg/g oil) (Morales et al., 2012b). Furthermore, the

194 chromatograms obtained by the ELSD in all samples of the three oils showed peaks that

195 interfered with the hydroxydienes. These peaks can be attributed to compounds that

196 form the unsaponifiable fraction of the oils and make it not possible to determine

197 hydroxydienes by light scattering detection.

198 In contrast to what has been found in purified lipids in the absence of antioxidants, i.e.,

199 FAME obtained from high oleic sunflower oil (Morales et al., 2012b), formation of

200 epoxides was not observed by the ELSD in the two monounsaturated oils, i.e. HOSO

201 and HSHOSO, during the IP. Occurrence of monoepoxystearates was however detected

202 in samples of both HOSO and HSHOSO that had already lost the tocopherol completely

203 (Figure 1). As a result, formation of epoxystearates at the conditions assayed appeared

204 to be inhibited in the presence of the tocopherol naturally occurring in the oils. This is

205 consistent with the results obtained by Rovellini and Cortesi (2004), who did not

206 observe the occurrence of epoxy compounds in a number of extra virgin olive oils

207 during storage.

208 In agreement with a previous study (Morales et al., 2012a), the concentration of

209 hydroperoxydienes showed excellent linear correlation with the PV during the IPs of the

210 oils (data not shown). Once tocopherol was completely depleted, the PV increased more

211 rapidly than the content of hydroperoxydienes (Figure 2), indicating the formation of

212 compounds with hydroperoxy functions other than those analyzed by HPLC, mainly

213 polymerization products and compounds with more than one oxygen-containing

214 functional group. The lower slopes for the two monounsaturated oils, i.e. HOSO and 
215 HSHOSO, during the IP suggest the presence of oleic hydroperoxides (Morales et al.,

216 2012a). The differences between the three oils were larger as the two monounsaturated

217 oils got closer to the end of the IPs, i.e., when the content of tocopherol was low. On the

218 contrary, no substantial differences were found in samples with relatively low oxidation

219 (PV $<50 \mathrm{meq} / \mathrm{kg})$ (Figure 2). As a conclusion, the results seem to indicate that the

220 oxidation of oleic acid in the monounsaturated oils was low in samples with low

221 oxidation levels, when tocopherol was present in substantial contents, and significant

222 from low concentrations of tocopherol. These results are coherent with those reported

223 elsewhere (Morales et al., 2012c), which showed that for a given global oxidation extent

224 the relative oxidation of oleic acid in FAME obtained from high oleic sunflower oil was

225 much less in the presence of $\alpha$-tocopherol. It was suggested that the hydrogen donor

226 capacity of methyl oleate was reduced in the presence of $\alpha$-tocopherol because the

227 antioxidant competes much more efficiently for peroxyl radicals (Kamal-Eldin et al., 228 2003).

229 Even though the relationship between the concentration of hydroperoxydienes and the

230 PV suggested the formation of oleic acid hydroperoxides at significant amounts in the

231 two monounsaturated oils at the end of the IP, no significant differences were found

232 between the contents of hydroperoxides determined by UV and light scattering

233 detection. The ELSD only showed significantly higher values in samples that had lost

234 tocopherols completely, i.e., in advanced oxidation extents (Tables 2-3). The absence of 235 compounds that can be used as markers for the oxidation of oleic acid, like 236 monoepoxystearates, support the low oxidation of such a substrate during the IPs of

237 HOSO and HSHOSO. Therefore, it can be said that, at the analytical conditions applied,

238 the ELSD does not enable the determination of the low concentrations of oleic acid

239 hydroperoxides that are formed in monounsaturated oils during the IPs. Apart from the 
240 low sensitivity of the ELSD, this can be attributed to the low global oxidation levels of

241 monounsaturated oils reached at the end of the IP compared to polyunsaturated oils

242 (Martín-Polvillo, Márquez-Ruiz, \& Dobarganes, 2004; Morales et al., 2010).

Oils containing oleic, linoleic and linolenic acids as oxidizable substrates

244 The presence of $\alpha$-linolenic acid at significant contents in vegetable oils such as those

245 dealt in the present study, SbO and RO, and its larger susceptibility to oxidation than 246 linoleic acid make it of interest to study the possibilities of the HPLC method to

247 evaluate their oxidation products. Likewise, the main oxidation products of linolenic 248 acid, i.e. hydroperoxides, have two conjugated double bonds and so the same 249 chromophore which is detected by UV in the method. Nevertheless, due to the high 250 reactivity of the hydroperoxides or peroxide precursors, bifunctional compounds, i.e. 251 with more than one oxygen-containing functional group, are formed in linolenic acid, 252 increasing considerably the degree of analytical complexity (Neff, Frankel, \& 253 Weisleder, 1981; Frankel, 2005). A few of these compounds like monocyclic 254 endoperoxides keep the conjugated diene structure, whereas others like bicyclic 255 endoperoxides lose it.

256 To explore the possibilities of the HPLC method in the evaluation of oxidation 257 products of linolenic acid in oils it was first necessary to study model lipids. In this 258 regard, samples of methyl linolenate were oxidized and analyzed directly by the 259 method. The analysis showed two major chromatographic peaks in the zone of 260 hydroperoxides (Figure 3A). These two peaks may be assigned to the so called external 261 hydroperoxides, 9- and 16-hydroperoxide, since the internal 12- and 13-hydroperoxides 262 form at lower amounts due to their participation in intramolecular 1,3-cyclization 263 reactions to give monocyclic endoperoxides (Frankel, 2005). These hydroperoxides 264 have two conjugated double bonds with cis,trans or trans, cis configuration and a third 
intact double bound. Unlike linoleic acid, the cis,trans-hydroperoxides of linolenate are

266 not readily isomerized to the trans,trans form, apparently because cyclization is much

267 more favored (Frankel, 2005). The chromatogram also showed wide bands at longer

268 retention times, in the zone of hydroxydienes, indicating the presence of numerous

269 compounds of high polarity, probably due to more than one oxygen-containing function

270 such as those of monocyclic endoperoxides or hydroperoxy epidioxides. Regarding

271 detection of compounds at $268 \mathrm{~nm}$, very minor peaks in the zone of ketodienes were

272 only detected in a wide range of oxidation levels (not shown), indicating that secondary

273 structures similar to those of linoleic acid were not significant. This fact can be

274 attributed to the much lower stability of methyl linolenate hydroperoxides, which

275 readily participate in reactions of intramolecular cyclization, originating endoperoxides,

276 and polymerization (Frankel, 2005). Nevertheless, formation of ketones other than

277 ketodienes should not be ruled out, being possible the formation of carbonyl groups in

278 molecules with more than one functional group. The ELSD only recorded the signals of

279 hydroperoxides (not shown), which were similar to those displayed by UV. Due to a

280 lower sensitivity, the bands corresponding to those at retention times longer than

281 hydroperoxydienes were not observed by light scattering detection.

282 In order to confirm that the bands observed at long retention times (Figure 3A) can

283 be assigned to hydroperoxy epidioxides, the formation of cyclization compounds was

284 inhibited by addition of a powerful hydrogen donor like $\alpha$-tocopherol at elevated

285 concentration $(5 \% \mathrm{p} / \mathrm{p})$ (Frankel, 2005). At these conditions, the internal peroxides are

286 readily transformed into their corresponding hydroperoxides and these in turn are

287 stabilized. The results obtained confirmed the starting hypothesis (Figure 3B). Only

288 peaks in the zone of hydroperoxides were recorded, although these unexpectedly eluted

289 in two peaks instead of four, probably due to coelution of compounds. Unlike the 
control sample, i.e., in the absence of antioxidants, both peaks presented similar areas, indicating that the four hydroperoxides eluted two by two, given that under these conditions they form at similar amounts (Frankel, 2005).

The concentration of $\alpha$-tocopherol tested was much larger than that commonly

294 found in edible vegetable oils $(<0.1 \% \mathrm{p} / \mathrm{p})$. For a more realistic situation, samples of 295 methyl linolenate containing $500 \mathrm{ppm} \alpha$-tocopherol were also studied. The

296 chromatograms obtained were quite similar to those for the control (Figure 3C). The

297 intramolecular cyclization was not completely inhibited at these conditions. Likewise,

298 secondary structures similar to those of methyl linoleate, i.e. ketodienes, were not 299 detected at $268 \mathrm{~nm}$ in a significant way (not shown).

301 linoleate (Figure 3D) showed overlapping between both groups of hydroperoxides

302 (Figure 3E), indicating that it is not possible to differentiate them. However, the 303 slightly higher polarity of linolenate hydroperoxides gave rise to a peak that eluted 304 immediately after the linoleate hydroperoxides. This could be used as a marker for 305 linolenic acid oxidation. In addition, there was expected overlapping between the bands 306 attributed to monocyclic endoperoxides and the hydroxydienes of methyl linoleate.

307 The results obtained show that the HPLC method enables the evaluation of simple 308 hydroperoxides of linoleic and linolenic acids as a whole. Given that both groups of 309 compounds have practically the same chromophore, an only response factor for 310 hydroperoxydienes, i.e., that reported elsewhere (Morales et al., 2010), was assumed for 311 quantitative purposes in oils.

312 Results for the oxidation of soybean oil ( $\mathrm{SbO})$ and rapeseed oil (RO) are presented in

313 Tables 4-5. Both oils exhibited quality parameters that were typical of fresh refined 
314 oils. Like the sunflower oils, the $\mathrm{RO}$ and $\mathrm{SbO}$ showed by light scattering detection

315 chromatographic peaks that overlapped with hydroxydienes. As opposed to the rest of

316 the oils tested in the present study, the chromatograms of SbO by ELSD also showed

317 peaks that overlapped with the ketodienes (Figure 4). Even though the SbO presented

318 quality parameters appropriate for well refined vegetable oils, with PV equal to zero and

319 a value for acidity of $0.04 \%$ on oleic acid, the HPLC analysis of the initial sample

320 remarkably exhibited the presence of hydroxydienes at relatively high concentrations

321 (Figure 4). Because the content of hydroperoxydienes was low, as it was also indicated

322 by the PV, the presence of these compounds may be attributed to modifications of

323 hydroperoxides in the crude oil during refining. Nevertheless, it is remarkable the fact

324 that apart from hydroxydienes other secondary oxidation compounds like ketodienes

325 were not observed. In this regard, previous studies have shown that hydroperoxydienes

326 are partially transformed into keto- and hydroxy- dienes at basic conditions (Morales et

327 al., 2012a).

328 The IPs determined by the total loss of tocopherols were 53 and 40 days for $\mathrm{SbO}$ and

329 RO, respectively (Tables 4-5). The contents of hydroperoxydienes accumulated during

330 the IP and the PV were larger for SbO, supporting the fact that polyunsaturated oils

331 accumulate more contents of oxidation products during the IP than monounsaturated

332 oils (Martín-Polvillo et al., 2004).

333 Apart from the hydroperoxides of linoleic acid, the chromatograms also showed

334 formation of linolenic hydroperoxides (Figure 5). Compared to RO, the presence of

335 linolenate hydroperoxides was not so evident in SbO, probably due to its larger content

336 of linoleic acid that resulted in higher relative proportions of linoleate hydroperoxides.

337 Similarly, the bands at longer retention times that were observed in oxidized methyl

338 linolenate (Figure 3C) were hardly noticeable in both oils because of the relatively high 
contents of linoleate hydroxydienes. In the zone of hydroxydienes, the chromatograms

340 of the ELSD (not shown) were not different from those of the initial samples, showing

341 peaks that may well be attributed to compounds of the unsaponifiable fraction.

342 Like in the sunflower oils, significant differences between the contents of 343 hydroperoxides determined by UV and light scattering detection were not found in the

344 two oils during the IP. Likewise, the ELSD only showed higher hydroperoxide

345 concentrations after the total depletion of tocopherols in the monounsaturated oil, i.e.,

346 RO. In agreement with the results found in the sunflower oils, these results suggest that

347 the oxidation of oleic acid was low in both poly- and mono- unsaturated oils during the

348 IP, i.e. in the presence of tocopherols.

349 Consistently with the sunflower oils, the relationship between the content of 350 hydroperoxydienes and the PV was practically linear in the $\mathrm{SbO}$ and RO during the IP 351 and after the exhaustion of tocopherols the PV increased more rapidly (not shown).

352 With the progressive loss of tocopherols the concentration of hydroperoxydienes was

353 significantly lower in the RO for a given PV, suggesting the formation of oleic acid 354 hydroperoxides (Morales et al., 2012a). However, hydroperoxides other than 355 hydroperoxydienes were not observed by the ELSD in the RO until tocopherol was 356 completely depleted.

357 As compared to results reported elsewhere for the relationship between 358 hydroperoxydienes and the PV in samples of pure linoleate hydroperoxides (Morales et 359 al., 2010), both SbO and RO showed lower hydroperoxydiene concentrations for a 360 given PV. This fact was indicative of the occurrence of compounds with hydroperoxy 361 functions other than those detected by either UV or the ELSD in the method, probably 362 due for the latter to its low sensitivity. Both monocyclic and bicyclic endoperoxides 363 contribute to increasing the PV. The low stability of simple linolenate hydroperoxides 
364 provided by the double bounds can also result in formation of hydroperoxides with

365 other additional oxygen functions and polymerization products bearing the hydroperoxy 366 group (Frankel, 2005).

\section{4. Conclusions}

368 Oxidation products of linoleate were predominant in all cases, whereas no significant 369 formation of oleate oxidation products was observed in the five oils in the presence of

370 substantial contents of the tocopherols naturally occurring, i.e., at low global oxidation 371 extents. The analysis of the main oxidation products of linoleate by the method applied 372 proved to be a good analytical approach to evaluate the global oxidation extent in oils 373 containing oleic and linoleic acids as the only oxidizable substrates present at 374 significant contents. For monounsaturated oils with low contents of linoleic acid, the 375 lower the oxidation extent, the better will be the analytical approach.

376 The analysis of oils containing linolenic acid suggested the formation of hydroperoxy 377 compounds other than those determined by the method, showing the low stability of 378 simple linolenate hydroperoxides and their participation in further reactions.

379 The HPLC method enables a more specific quality determination of fresh refined oils

380 than the control parameters normally applied in the industry, such as the PV. Detection 381 of secondary oxidation products, which can act as oxidation catalysts, may account for 382 losses of stability unexpectedly found in fresh refined oils. 


\section{Acknoledgements}

385 This work was funded by "Junta de Andalucía" through project P09-AGR-4622 and by

386 “Ministerio de Ciencia e Innovación” through project AGL 2010-18307.

387 
AOCS (1998). Standard Method Ch 5-91. In AOCS Official methods and recommended practices of the American Oil Chemists' Society (5th ed.). Champaign: AOCS Press.

392

Dobarganes, M. C., \& Márquez Ruiz, G. (2003). Oxidized fats in foods. Current Opinion in Clinical Nutrition and Metabolic Care, 6,157-163.

Frankel, E.N. (2005). Lipid oxidation, 2nd edn. Edited by Frankel E.N. The Oily Press, Dundee, UK.

IUPAC (1992). Standard methods for the analysis of oils, fats and derivatives (7th ed.). Oxford: Blackell.

Kamal-Eldin, A., Mäkinen, M., Lampi., A.-M. (2003). The challenging contribution of hydroperoxides to the lipid oxidation mechanism. In A. Kamal-Eldin (Ed.), Lipid Oxidation Pathways (pp. 1-36). Illinois: AOCS Press.

Kanazawa, A., Sawa, T., Akaike, T., \& Maeda, H. (2002). Dietary lipid peroxidation and DNA damage in colon carcinogenesis. European Journal of Lipid Science and Technology, 104, 439- 447.

Márquez-Ruiz, G., \& Dobarganes, M. C. (2005). Analysis of non-volatile lipid oxidation compounds by high-performance size-exclusion chromatography. In A. Kamal-Eldin and J. Pokorny (Ed.), Analysis of Lipid Oxidation (pp. 40-69). Illinois: AOCS Press.

Márquez-Ruiz, G., Martín-Polvillo, M., \& Dobarganes, M. C. (1996). Quantitation of oxidized triglyceride monomers and dimers as a useful measurement for early and advanced stages of oxidation. Grasas y Aceites, 47, 48-53.

Martín-Polvillo, M., Márquez-Ruiz, G., \& Dobarganes, M. C. (2004). Oxidative stability of sunflower oils differing in unsaturation degree during long-term storage at room temperature. Journal of the American Oil Chemists' Society, 81, 577-583.

Morales, A., Dobarganes, C., Márquez-Ruiz, G., \& Velasco, J. (2010). Quantitation of hydroperoxy-, keto- and hydroxy-dienes during oxidation of FAMEs from high- 

Society, 87, 1271-1279.

418 Morales, A., Marmesat, S., Dobarganes, C., Márquez-Ruiz, G., \& Velasco, J. (2012a). 419 Quantitative analysis of hydroperoxy-, keto- and hydroxy-dienes in refined vegetable oils. Journal of Chromatography A, 1229, 190-197.

Morales, A., Marmesat, S., Dobarganes, C., Márquez-Ruiz, G., \& Velasco, J. (2012b). chromatography determination of FAME oxidation products. Journal of Chromatography A, 1254, 62-70.

Morales, A., Dobarganes, C., Márquez-Ruiz, G., \& Velasco, J. (2012c). Formation of hydroperoxy-, keto- and hydroxy-dienes in FAME from oils: influence of temperature and addition of $\alpha$-tocopherol. Journal of the American Oil Chemists' Society, 89, 675-684.

Neff, W.E., Frankel, E.N., \& Weisleder, D. (1981). High-pressure liquidchromatography of auto-oxidized lipids .2. hydroperoxy-cyclic peroxides and other secondary products from methyl linolenate. Lipids, 16, 439-448.

432 Rovellini, P., \& Cortesi, N. (2004). Oxidative status of extra virgin olive oils: HPLC 433 evaluation. Italian Journal of Food Science, 16, 333-342. 
436 Fig. 1 HPLC-ELSD chromatograms of HOSO oxidized at $40^{\circ} \mathrm{C}$ for 82 days (A) and 437 HSHOSO for 143 days $(\mathbf{B})$.

438 Fig. 2 Formation of hydroperoxydienes (filled) and loss of tocopherol (hollow) relative 439 to the PV during oxidation at $40^{\circ} \mathrm{C}$ in HLSO (circles), HOSO (triangles) and HSHOSO 440 (squares).

441 Fig. 3 HPLC-UV 234 chromatograms of samples of methyl linolenate oxidized at 442 ambient temperature in the absence of antioxidants (A), containing $5 \mathrm{wt} \%(\mathbf{B})$ and 500 443 ppm of $\alpha$-tocopherol (C). HPLC-UV 234 chromatograms of a sample containing methyl 444 linoleate hydroperoxides and methyl 13-hydroxy-(Z)-9,(E)-11-octadecadienate (D) and 445 a sample containing a mixture of samples C and D (E).

446 Fig. 4 HPLC-UV-ELSD chromatograms of the initial sample of SbO.

447 Fig. 5 HPLC-UV 234 chromatograms of $\mathrm{SbO}$ oxidized at $40^{\circ} \mathrm{C}$ for 53 days (A) and RO 448 for 40 days $(\mathbf{B})$. 
Table 1 Autoxidation of high-linoleic sunflower oil (HLSO) at $40{ }^{\circ} \mathrm{C}$ in the dark.

\begin{tabular}{|c|c|c|c|c|c|c|c|c|}
\hline \multirow[b]{2}{*}{$\begin{array}{l}\text { Time } \\
\text { (days) }\end{array}$} & \multirow[b]{2}{*}{$\begin{array}{l}\text { Pol }^{\mathrm{a}} \\
(\%)\end{array}$} & \multirow[b]{2}{*}{$\begin{array}{c}\alpha \text {-Toc } \\
(\mathrm{mg} / \mathrm{kg})\end{array}$} & \multirow[b]{2}{*}{$\begin{array}{c}\mathbf{P V}^{\mathbf{b}} \\
(\mathrm{meq} / \mathrm{kg})\end{array}$} & \multirow[b]{2}{*}{$\mathbf{K}_{232}{ }^{\mathrm{c}}$} & \multicolumn{3}{|c|}{$\mathbf{U V}$} & \multirow{2}{*}{$\begin{array}{c}\text { ELSD } \\
\text { Hydroperoxides } \\
(\mathrm{mg} / \mathrm{g})\end{array}$} \\
\hline & & & & & $\begin{array}{c}\text { Hydroperoxy- } \\
\text { dienes } \\
(\mathrm{mg} / \mathrm{g})\end{array}$ & $\begin{array}{c}\text { Keto- } \\
\text { dienes } \\
(\mathrm{mg} / \mathrm{g})\end{array}$ & $\begin{array}{c}\text { Hydroxy- } \\
\text { dienes } \\
(\mathrm{mg} / \mathrm{g})\end{array}$ & \\
\hline 0 & 0.6 & 614 & 1.7 & 2.8 & $0.08 \pm 0.01$ & $0.11 \pm 0.01$ & $0.37 \pm 0.01$ & $\mathrm{ND}^{\mathrm{d}}$ \\
\hline 7 & 0.6 & 611 & 30.7 & 6.3 & $3.19 \pm 0.02 \mathrm{a}$ & $0.31 \pm 0.01$ & $0.39 \pm 0.02$ & $3.20 \pm 0.48 \mathrm{a}$ \\
\hline 17 & 0.7 & 432 & 91.7 & 13.5 & $10.86 \pm 0.14 \mathrm{a}$ & $0.81 \pm 0.06$ & $0.48 \pm 0.05$ & $11.07 \pm 0.28 \mathrm{a}$ \\
\hline 21 & 0.8 & 349 & 125 & 17.3 & $13.77 \pm 0.79 a$ & $1.02 \pm 0.04$ & $0.58 \pm 0.00$ & $14.10 \pm 1.00 \mathrm{a}$ \\
\hline 31 & 0.9 & 93 & 188 & 24.0 & $22.45 \pm 0.80 \mathrm{a}$ & $1.47 \pm 0.04$ & $0.66 \pm 0.00$ & $23.92 \pm 1.20 \mathrm{a}$ \\
\hline 35 & 1.0 & 25 & 216 & 41.1 & $24.12 \pm 1.27 \mathrm{a}$ & $1.57 \pm 0.04$ & $0.74 \pm 0.01$ & $25.25 \pm 1.59 \mathrm{a}$ \\
\hline
\end{tabular}

a polymers, ${ }^{b}$ peroxide value, ${ }^{c}$ specific extinction at $232 \mathrm{~nm}$, ${ }^{d}$ not detected. Different letters for hydroperoxy-dienes and hydroperoxides for a given sample show significant differences $(p<0.05)$. 
Table 2 Autoxidation of high-oleic sunflower oil (HOSO) at $40{ }^{\circ} \mathrm{C}$ in the dark.

\begin{tabular}{|c|c|c|c|c|c|c|c|c|}
\hline \multirow{2}{*}{$\begin{array}{l}\text { Time } \\
\text { (days) }\end{array}$} & \multirow{2}{*}{$\begin{array}{l}\text { Pol } \\
(\%)\end{array}$} & \multirow{2}{*}{$\begin{array}{c}\alpha-\text { Toc } \\
(\mathrm{mg} / \mathrm{kg})\end{array}$} & \multirow{2}{*}{$\begin{array}{c}\text { PV } \\
(\mathrm{meq} / \mathrm{kg})\end{array}$} & \multirow[b]{2}{*}{$\mathbf{K}_{232}$} & \multicolumn{3}{|c|}{$\mathbf{U V}$} & \multirow{2}{*}{$\begin{array}{c}\text { ELSD } \\
\begin{array}{c}\text { Hydroperoxides } \\
(\mathrm{mg} / \mathrm{g})\end{array}\end{array}$} \\
\hline & & & & & $\begin{array}{c}\text { Hydroperoxy- } \\
\text { dienes } \\
(\mathrm{mg} / \mathrm{g})\end{array}$ & $\begin{array}{c}\text { Keto- } \\
\text { dienes } \\
(\mathrm{mg} / \mathrm{g})\end{array}$ & $\begin{array}{c}\text { Hydroxy- } \\
\text { dienes } \\
(\mathrm{mg} / \mathrm{g})\end{array}$ & \\
\hline 0 & 0.5 & 630 & 2.4 & 2.3 & $0.16 \pm 0.01$ & $0.13 \pm 0.00$ & $0.14 \pm 0.02$ & ND \\
\hline 10 & 0.5 & 566 & 17.0 & 3.7 & $1.33 \pm 0.01 \mathrm{a}$ & $0.15 \pm 0.01$ & $0.12 \pm 0.01$ & $1.35 \pm 0.12 \mathrm{a}$ \\
\hline 21 & 0.6 & 483 & 30.9 & 5.5 & $3.06 \pm 0.26 \mathrm{a}$ & $0.25 \pm 0.01$ & $0.16 \pm 0.02$ & $2.95 \pm 0.46 \mathrm{a}$ \\
\hline 36 & 0.6 & 356 & 57.8 & 8.0 & $5.31 \pm 0.06 \mathrm{a}$ & $0.43 \pm 0.03$ & $0.23 \pm 0.01$ & $5.71 \pm 0.35 \mathrm{a}$ \\
\hline 55 & 0.7 & 158 & 83.9 & 10.4 & $7.75 \pm 0.31 \mathrm{a}$ & $0.57 \pm 0.02$ & $0.36 \pm 0.02$ & $7.55 \pm 0.64 \mathrm{a}$ \\
\hline 72 & 0.8 & 10 & 110 & 12.6 & $9.42 \pm 0.34 \mathrm{a}$ & $0.77 \pm 0.01$ & $0.46 \pm 0.02$ & $9.45 \pm 0.62 \mathrm{a}$ \\
\hline 82 & 1.4 & 0 & 157 & 21.7 & $12.21 \pm 0.11 \mathrm{a}$ & $0.98 \pm 0.06$ & $0.67 \pm 0.05$ & $13.27 \pm 0.77 b$ \\
\hline
\end{tabular}

For abbreviations see Table 1. Different letters for hydroperoxy-dienes and hydroperoxides for a given sample show significant differences $(p<0.05)$. 
Table 3 Autoxidation of high-stearic high-oleic sunflower oil (HSHOSO) at $40{ }^{\circ} \mathrm{C}$ in the dark.

\begin{tabular}{|c|c|c|c|c|c|c|c|c|}
\hline \multirow{2}{*}{$\begin{array}{l}\text { Time } \\
\text { (days) }\end{array}$} & \multirow{2}{*}{$\begin{array}{l}\text { Pol } \\
(\%)\end{array}$} & \multirow{2}{*}{$\begin{array}{c}\alpha-\text { Toc } \\
(\mathrm{mg} / \mathrm{kg})\end{array}$} & \multirow{2}{*}{$\begin{array}{c}\text { PV } \\
(\mathrm{meq} / \mathrm{kg})\end{array}$} & \multirow[b]{2}{*}{$K_{232}$} & \multicolumn{3}{|c|}{$\mathbf{U V}$} & \multirow{2}{*}{$\begin{array}{c}\text { ELSD } \\
\text { Hydroperoxides } \\
(\mathrm{mg} / \mathrm{g})\end{array}$} \\
\hline & & & & & $\begin{array}{c}\text { Hydroperoxy- } \\
\text { dienes } \\
(\mathrm{mg} / \mathrm{g})\end{array}$ & $\begin{array}{c}\text { Keto- } \\
\text { dienes } \\
(\mathrm{mg} / \mathrm{g})\end{array}$ & $\begin{array}{c}\text { Hydroxy- } \\
\text { dienes } \\
(\mathrm{mg} / \mathrm{g})\end{array}$ & \\
\hline 0 & 0.4 & 561 & 1.6 & 2.5 & $0.13 \pm 0.01$ & $0.04 \pm 0.00$ & $<0.05$ & ND \\
\hline 31 & 0.4 & 496 & 18.1 & 3.7 & $1.50 \pm 0.07 \mathrm{a}$ & $0.23 \pm 0.01$ & $0.12 \pm 0.01$ & $2.00 \pm 0.07 b$ \\
\hline 55 & 0.7 & 395 & 33.1 & 4.6 & $2.47 \pm 0.10 \mathrm{a}$ & $0.44 \pm 0.03$ & $0.20 \pm 0.01$ & $2.46 \pm 0.02 \mathrm{a}$ \\
\hline 80 & 0.8 & 237 & 52.1 & 5.9 & $3.97 \pm 0.13 \mathrm{a}$ & $0.60 \pm 0.01$ & $0.28 \pm 0.01$ & $4.25 \pm 0.34 \mathrm{a}$ \\
\hline 101 & 0.9 & 129 & 63.6 & 6.7 & $4.81 \pm 0.09 \mathrm{a}$ & $0.76 \pm 0.08$ & $0.37 \pm 0.01$ & $5.17 \pm 0.28 \mathrm{a}$ \\
\hline 143 & 1.5 & 0 & 130 & 14.9 & $6.09 \pm 0.40 \mathrm{a}$ & $0.99 \pm 0.02$ & $0.59 \pm 0.03$ & $8.29 \pm 0.30 b$ \\
\hline
\end{tabular}

For abbreviations see Table 1. Different letters for hydroperoxy-dienes and hydroperoxides for a given sample show significant differences $(p<0.05)$. 
Table 4 Autoxidation of soybean oil $(\mathrm{SbO})$ at $40{ }^{\circ} \mathrm{C}$ in the dark.

\begin{tabular}{|c|c|c|c|c|c|c|c|c|}
\hline \multirow{2}{*}{$\begin{array}{l}\text { Time } \\
\text { (days) }\end{array}$} & \multirow{2}{*}{$\begin{array}{l}\text { Pol } \\
(\%)\end{array}$} & \multirow{2}{*}{$\begin{array}{c}\text { Toc } \\
(\mathrm{mg} / \mathrm{kg})\end{array}$} & \multirow{2}{*}{$\begin{array}{c}\text { PV } \\
\text { (meq/kg) }\end{array}$} & \multirow[b]{2}{*}{$\mathbf{K}_{232}$} & \multicolumn{3}{|c|}{$\mathbf{U V}$} & \multirow{2}{*}{$\begin{array}{c}\text { ELSD } \\
\begin{array}{c}\text { Hydroperoxides } \\
(\mathrm{mg} / \mathrm{g})\end{array}\end{array}$} \\
\hline & & & & & $\begin{array}{c}\text { Hydroperoxy- } \\
\text { dienes } \\
(\mathrm{mg} / \mathrm{g})\end{array}$ & $\begin{array}{l}\text { Keto- } \\
\text { dienes } \\
(\mathrm{mg} / \mathrm{g})\end{array}$ & $\begin{array}{c}\text { Hydroxy- } \\
\text { dienes } \\
(\mathrm{mg} / \mathrm{g})\end{array}$ & \\
\hline 0 & 0.5 & 915 & 0 & 4.5 & $0.07 \pm 0.03$ & $0.07 \pm 0.01$ & $1.02 \pm 0.02$ & ND \\
\hline 11 & 0.7 & 853 & 23.7 & 5.7 & $1.85 \pm 0.09 \mathrm{a}$ & $0.17 \pm 0.02$ & $1.10 \pm 0.04$ & $2.16 \pm 0.20 \mathrm{~b}$ \\
\hline 21 & 0.6 & 667 & 92.4 & 11.2 & $6.99 \pm 0.11 \mathrm{a}$ & $0.56 \pm 0.04$ & $1.19 \pm 0.02$ & $8.35 \pm 0.27 \mathrm{~b}$ \\
\hline 33 & 0.7 & 417 & 160 & 18.5 & $13.19 \pm 0.26 \mathrm{a}$ & $1.04 \pm 0.07$ & $1.42 \pm 0.06$ & $13.65 \pm 0.35 \mathrm{a}$ \\
\hline 40 & 1.0 & 260 & 219 & 20.1 & $15.94 \pm 0.73 \mathrm{a}$ & $1.41 \pm 0.07$ & $1.62 \pm 0.11$ & $16.65 \pm 0.66 \mathrm{a}$ \\
\hline 46 & 1.3 & 144 & 275 & 27.3 & $20.15 \pm 0.78 \mathrm{a}$ & $1.86 \pm 0.12$ & $1.88 \pm 0.02$ & $21.83 \pm 1.69 \mathrm{a}$ \\
\hline 49 & 1.5 & 94 & 335 & 27.9 & $24.77 \pm 0.23 \mathrm{a}$ & $2.21 \pm 0.03$ & $2.24 \pm 0.05$ & $26.61 \pm 0.58 b$ \\
\hline 53 & 2.4 & 0 & 492 & 36.2 & $30.62 \pm 1.24 \mathrm{a}$ & $2.97 \pm 0.03$ & $3.53 \pm 0.23$ & $32.50 \pm 1.39 \mathrm{a}$ \\
\hline
\end{tabular}

For abbreviations see Table 1. The initial sample presented 151, 19, 560 and $185 \mathrm{mg} / \mathrm{kg}$ of $\alpha-, \beta-, \gamma-$ and $\delta$-tocopherol, respectively. Different letters for hydroperoxy-dienes and hydroperoxides for a given sample show significant differences $(p<0.05)$. 
Table 5 Autoxidation of rapeseed oil (RO) at $40{ }^{\circ} \mathrm{C}$ in the dark.

\begin{tabular}{|c|c|c|c|c|c|c|c|c|}
\hline \multirow{2}{*}{$\begin{array}{l}\text { Time } \\
\text { (days) }\end{array}$} & \multirow{2}{*}{$\begin{array}{l}\text { Pol } \\
(\%)\end{array}$} & \multirow{2}{*}{$\begin{array}{c}\text { Toc } \\
\text { (mg/kg) }\end{array}$} & \multirow{2}{*}{$\begin{array}{c}\text { PV } \\
\text { (meq/kg) }\end{array}$} & \multirow[b]{2}{*}{$K_{232}$} & \multicolumn{3}{|c|}{$\mathbf{U V}$} & \multirow{2}{*}{$\begin{array}{c}\text { ELS } \\
\text { Hydroperoxides } \\
(\mathrm{mg} / \mathrm{g})\end{array}$} \\
\hline & & & & & $\begin{array}{c}\text { Hydroperoxy- } \\
\text { dienes } \\
(\mathrm{mg} / \mathrm{g})\end{array}$ & $\begin{array}{c}\text { Keto- } \\
\text { dienes } \\
(\mathrm{mg} / \mathrm{g})\end{array}$ & $\begin{array}{c}\text { Hydroxy- } \\
\text { dienes } \\
(\mathrm{mg} / \mathrm{g})\end{array}$ & \\
\hline 0 & 0.3 & 522 & 1.4 & 4.29 & $0.10 \pm 0.03$ & $<0.02$ & ND & ND \\
\hline 11 & 0.5 & 450 & 35 & 6.41 & $2.46 \pm 0.13 \mathrm{a}$ & $<0.02$ & ND & $2.24 \pm 0.18 \mathrm{a}$ \\
\hline 18 & 0.6 & 312 & 81 & 11.41 & $5.07 \pm 0.06 \mathrm{a}$ & $0.37 \pm 0.05$ & $0.17 \pm 0.01$ & $4.77 \pm 0.24 \mathrm{a}$ \\
\hline 25 & 0.6 & 180 & 114 & 12.77 & $6.41 \pm 0.32 \mathrm{a}$ & $0.44 \pm 0.08$ & $0.24 \pm 0.03$ & $6.04 \pm 0.45 \mathrm{a}$ \\
\hline 40 & 1.2 & 0 & 203 & 16.28 & $10.25 \pm 0.03 a$ & $0.78 \pm 0.02$ & $0.73 \pm 0.03$ & $15.85 \pm 0.40 b$ \\
\hline 46 & 4.3 & 0 & 611 & 32.56 & $24.24 \pm 0.34 \mathrm{a}$ & $2.10 \pm 0.02$ & $3.71 \pm 0.01$ & $35.19 \pm 0.10 b$ \\
\hline
\end{tabular}

For abbreviations see Table 1. The initial sample presented 252 and $270 \mathrm{mg} / \mathrm{kg}$ of $\alpha$ - and $\gamma$-tocopherol, respectively. Different letters for hydroperoxy-dienes and hydroperoxides for a given sample show significant differences $(p<0.05)$. 

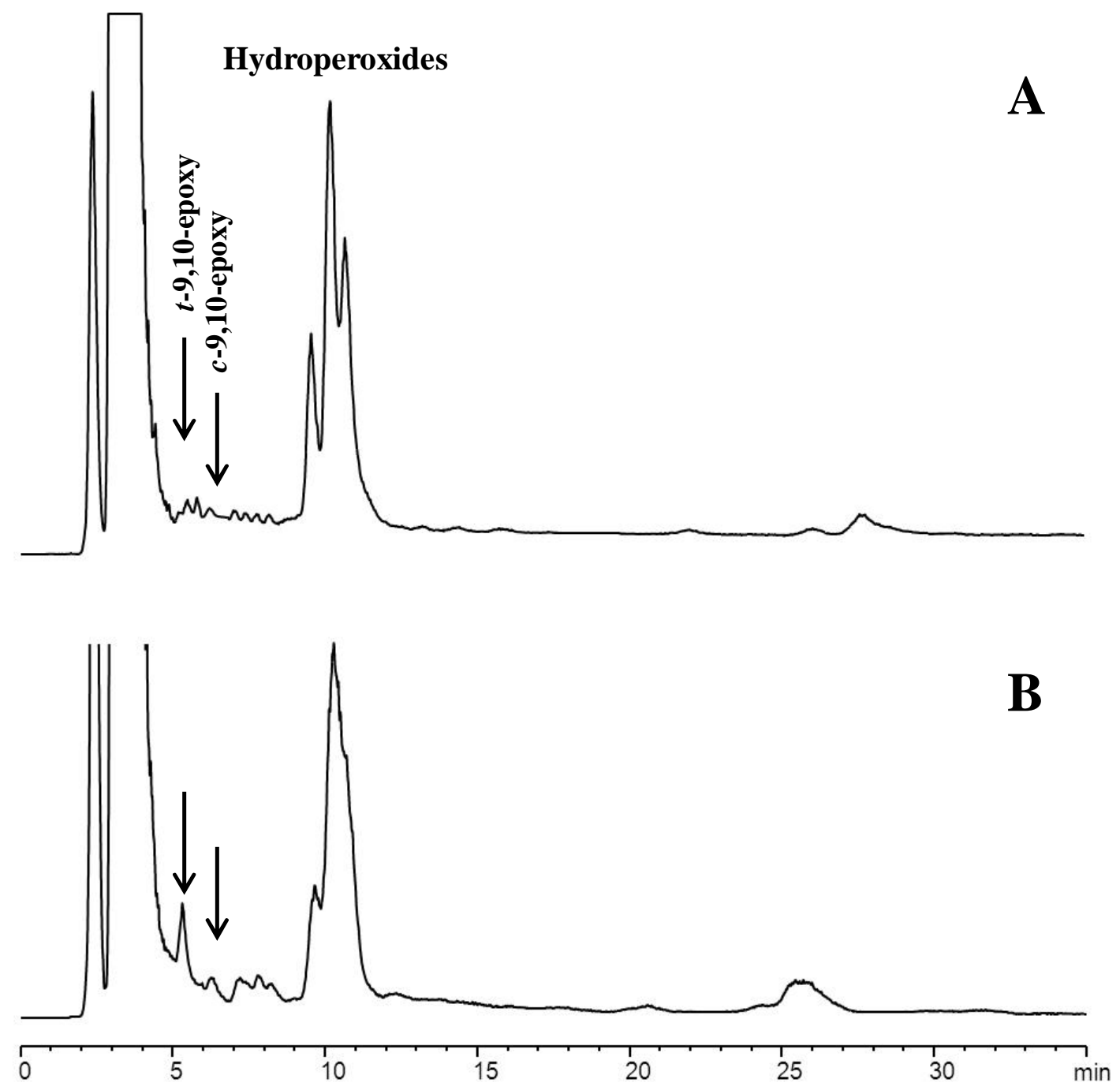

Figure 1 


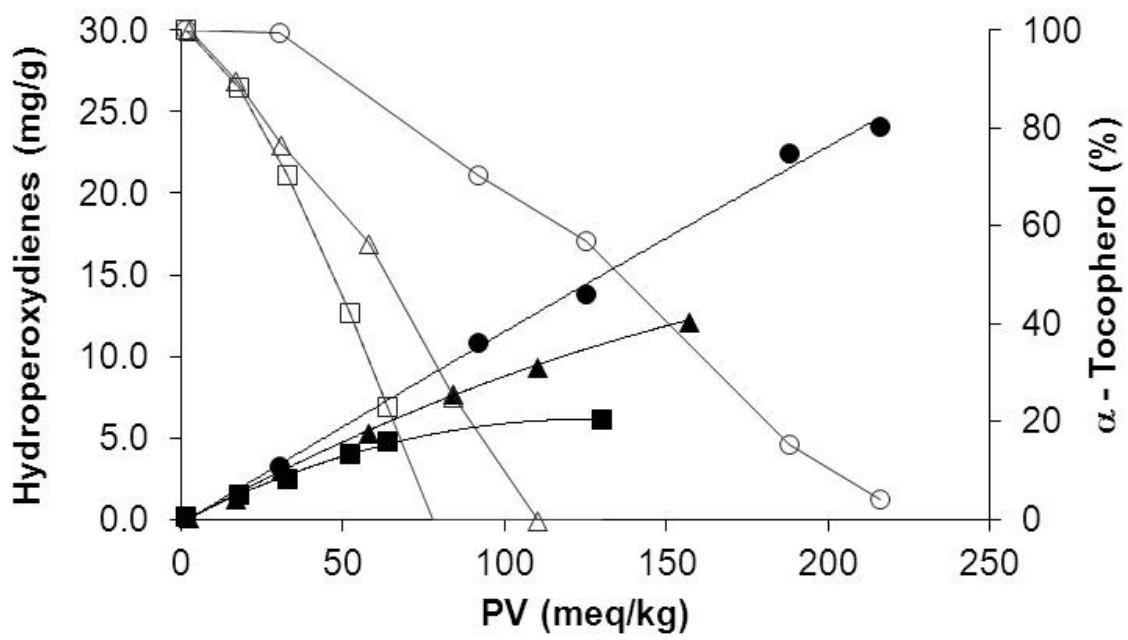

Figure 2 


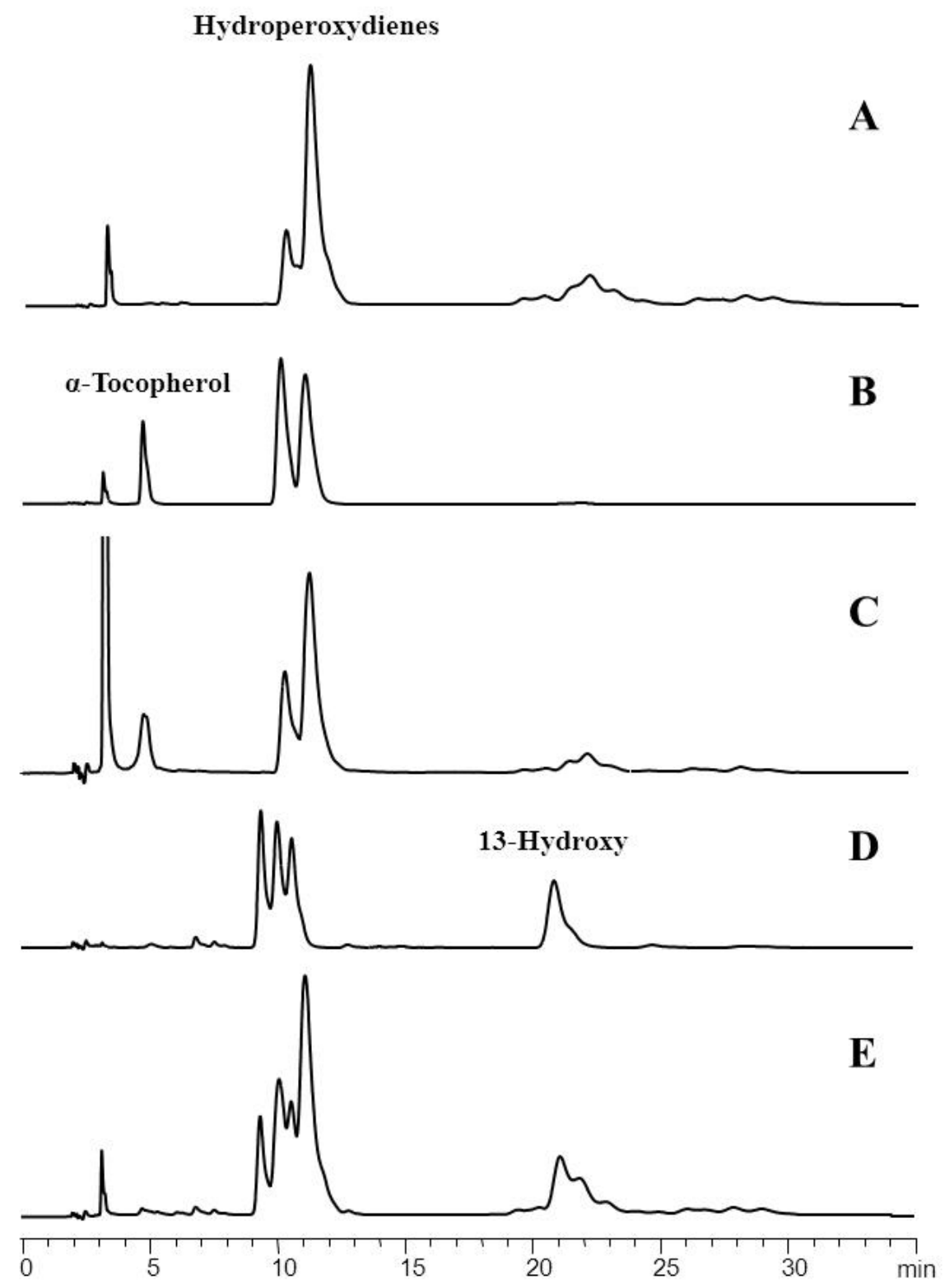

Figure 3 

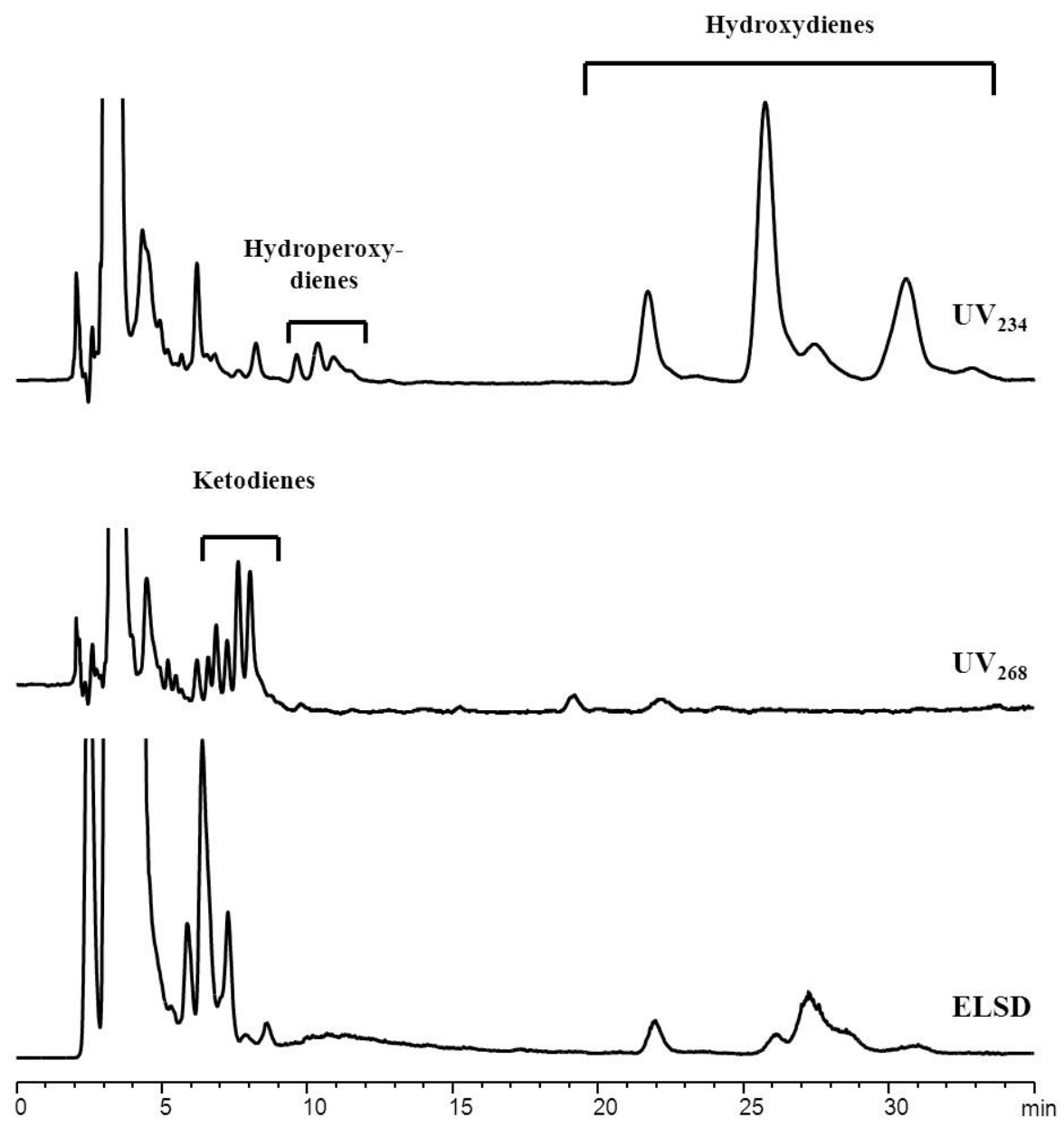

Figure 4 


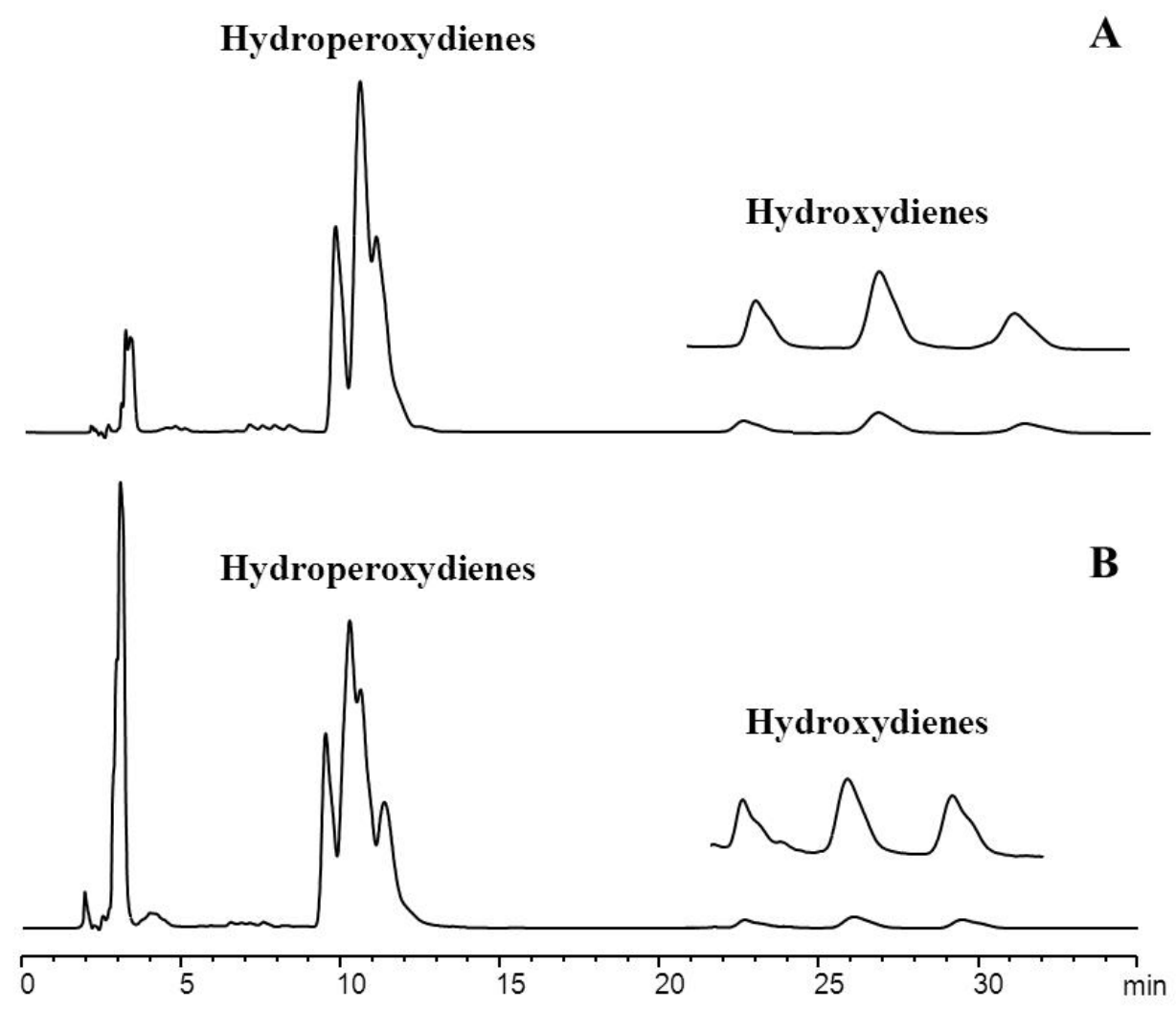

Figure 5 